\title{
Near-Earth substorm features from multiple satellite observations
}

\author{
A. T. Y. Lui, ${ }^{1}$ M. Volwerk, ${ }^{2,3}$ M. W. Dunlop, ${ }^{4}$ I. V. Alexeev, ${ }^{5}$ A. N. Fazakerley, ${ }^{5}$ \\ A. P. Walsh, ${ }^{5}$ M. Lester, ${ }^{6}$ A. Grocott, ${ }^{6}$ C. Mouikis, ${ }^{7}$ M. G. Henderson, ${ }^{8}$ L. M. Kistler, ${ }^{7}$ \\ C. Shen, ${ }^{9}$ J. K. Shi, ${ }^{9}$ T. L. Zhang, ${ }^{2}$ and H. Rème ${ }^{10}$ \\ Received 19 August 2007; revised 3 January 2008; accepted 7 February 2008; published 16 May 2008.
}

[1] We investigate a substorm on 3 October 2004 during which 11 satellites were located in near-Earth magnetotail $\left(X_{\mathrm{GSM}}>-10 R_{\mathrm{E}}\right)$. Double Star 1 (TC-1), Cluster, and LANL-97 satellites were closely aligned in the dawn-dusk direction $\left(<1 R_{\mathrm{E}}\right.$ apart) for this conjunction. After substorm expansion onset, TC-1 observed plasma sheet thinning at $X \approx$ $-5.5 R_{\mathrm{E}}$ and later detected signature of plasma flow shear that may be associated with an auroral arc. Analysis of the dawn-dusk magnetic perturbations from GOES-10 and Polar suggests that these could be caused by a substorm current system consisting of not only the azimuthal closure of field-aligned currents (the substorm current wedge) but also the meridional closure of field-aligned currents. The temporal sequence of substorm activity (particle injection, current disruption, and dipolarization) revealed by these satellites indicates that the substorm expansion activity was initiated close to the Earth and spread later to further downstream distances. Furthermore, TC-1 and Cluster data show that there is no close relationship between some dipolarizations and Earthward plasma flows in the near-Earth region. The overall development of substorm activity is in agreement with the near-Earth initiation model for substorms. A temporal evolution of the magnetic field reconfiguration and plasma boundary motion during this substorm is constructed from these observations.

Citation: Lui, A. T. Y., et al. (2008), Near-Earth substorm features from multiple satellite observations, J. Geophys. Res., 113, A07S26, doi:10.1029/2007JA012738.

\section{Introduction}

[2] The physical process responsible for the substorm expansion onsets [Akasofu, 1964] has puzzled space scientists for more than 4 decades. There are two main contemporary substorm models. One calls for the occurrence of magnetic reconnection at a downstream distance of $\sim 20 R_{\mathrm{E}}$ in the magnetotail. The resulting earthward directed plasma jet impinges on the magnetic field in the inner magnetosphere to form an eastward inertial current in the neutral sheet and lead to the substorm current wedge [Haerendel, 1992; Shiokawa et al., 1997; Nagai et al., 1998; Birn et al.,

\footnotetext{
${ }^{1}$ Johns Hopkins University Applied Physics Laboratory, Laurel, Maryland, USA.

${ }^{2}$ Space Research Institute, Austrian Academy of Sciences, Graz, Austria.

${ }^{3}$ Max Planck Institute for Extraterrestrial Physics, Garching, Germany.

${ }^{4}$ Space Science and Technology Department, RAL, Didcot, UK.

${ }^{5}$ Mullard Space Science Laboratory, Dorking, UK.

${ }^{6}$ Department of Physics and Astronomy, University of Leicester, Leicester, UK.

${ }^{7}$ Space Science Center, University of New Hampshire, Durham, New Hampshire, USA.

${ }^{8}$ Los Alamos National Laboratory, Los Alamos, New Mexico, USA.

${ }^{9}$ Center for Space Science and Applied Research, Chinese Academy of Sciences, Beijing, China.

${ }^{10} \mathrm{CESR} / \mathrm{CNRS}$, Toulouse, France.

Copyright 2008 by the American Geophysical Union. 0148-0227/08/2007JA012738\$09.00
}

1999; Nakamura et al., 2001, 2002]. The other invokes a plasma process different from magnetic reconnection in the near-Earth region that allows the cross-tail current to be disrupted, giving rise to the substorm current wedge. Magnetic reconnection may occur further down the magnetotail as current disruption spreads further downstream [e.g., Lui, 1991, 1996; Roux et al., 1991; Erickson, 1995; Cheng and Lui, 1998; Erickson et al., 2000; Bristow et al., 2003]. Current disruption can also generate meridional closure currents [Lui and Kamide, 2003]. The former and latter models are referred to as the midtail initiation and the nearEarth initiation, respectively.

[3] The transition region in which the tail-like magnetic field configuration changes to the dipolar magnetic field configuration bears significance to both models. In the midtail initiation model, the transition region is where the braking of a plasma jet leads to an eastward inertial current and drives the substorm current wedge initially. In the nearEarth initiation model, the transition region is the site where the substorm onset process occurs. One major deficiency contributing to this substorm controversy is the scarcity of full-suite plasma measurements in the transition region to examine the plasma dynamics there due to the fact that very few satellites traverse the region. This difficulty in examining substorm behavior in the region is compounded by the spatial localization of these disturbances. Earthward directed plasma jets are expected to be rather narrow in the dawndusk direction [e.g., Angelopoulos et al., 1996; Nakamura 
et al., 2004]. Current disruptions are also observed to occur in very spatially limited regions [e.g., Lui et al., 1988; Lopez and Lui, 1990; Ohtani et al., 1998]. The advent of the Double Star Program has contributed significantly by providing valuable measurements in the transition region. Further relief to this deficiency in observations is expected from the recently launched NASA mission THEMIS (Time History of Events and Macroscale Interactions during Substorms). Its primary target is to resolve this substorm controversy by examining the propagation direction of substorm disturbances in the magnetotail with five satellites, three of which are placed with apogee near the transition region.

[4] Prior to the availability of data from the Double Star Program and the THEMIS mission to address the location of substorm onset process, there were occasions in which valuable information about time development of substorm phenomena could be extracted from fortuitous satellite conjunctions [e.g., Lui et al., 2000, 2007; Sergeev et al., $2005,2007]$. In this paper, we present analysis of a substorm event during which 11 satellites were in close proximity with each other in the near-Earth magnetotail. The results shed considerable light on the substorm dynamics in the near-Earth magnetotail that can be used to differentiate the two models.

\section{Observations}

\subsection{Ground-Based Observations}

[5] The ground magnetic activity related to substorms on 3 October 2004 is exemplified by the AU/AL indices shown in Figure 1a. Several noticeable enhancements in these indices occurred during that day. The shaded region highlights the time interval when favorable satellite conjunction occurred. The substorm expansion onset for this conjunction event was at $\sim 1048 \mathrm{UT}$, with the peak disturbance of the AL index reached at $\sim 1119$ UT. The occurrence of repeated substorm activity from $\sim 0500$ UT onward for the day is expected since data from the Wind satellite (not shown) indicate that the interplanetary magnetic field became southward at $\sim 0339$ UT and remained mostly southward for $\sim 14 \mathrm{~h}$. Figure $1 \mathrm{~b}$ shows magnetograms from several magnetic stations at the auroral latitudes. The triangle underneath each trace marks the magnetic local midnight for that station. The substorm activity seen in the AU/AL indices was registered by the CMO (College) station that was in the early postmidnight magnetic local time (MLT) at substorm expansion onset (1048 UT). Most of the other late postmidnight stations (e.g., BLC and PBQ) did not detect significant magnetic perturbations, with the notable exception of FCC that observed rather continuous but weak magnetic activity. In addition to these magnetic stations in the northern hemisphere, similar magnetic activity with onset at 1048 UT was recorded at Dumont d'Uroille station in the southern hemisphere.

\subsection{Distribution of Satellites in the Magnetosphere}

[6] The projections of satellite locations on the $X Y$ - and $X Z$-planes of the Geocentric Solar Magnetospheric (GSM) coordinate system in the nightside magnetosphere during this interval are indicated in Figure 2. There were 11 satellites altogether, eight in the premidnight MLT (four Cluster satellites, two Double Star satellites, Polar, and the Los Alamos satellite LANL-97), one near the midnight meridian (LANL-91), and two in the postmidnight MLT (GOES-10 and Geotail). In particular, three premidnight satellites had nearly the same $Y_{\mathrm{GSM}}$-coordinate value $\left(<1 R_{\mathrm{E}}\right.$ difference), i.e., the $Y_{\mathrm{GSM}}$ values at $1048 \mathrm{UT}$ for Cluster (SAMBA: C3), Double Star 1 (also known as TC-1), and LANL-97 are 4.6, 5.3, and 5.0 $R_{\mathrm{E}}$, respectively. The coordinate system adopted throughout this study is GSM unless stated otherwise.

\subsection{Geosynchronous Particle Observations}

[7] Energetic proton fluxes from the Los Alamos geosynchronous satellites on that day are shown in Figure 3. Two satellites (LANL-91, LANL-97) were in the night sector at $\sim 1048$ UT and observed substorm injections at about the same time. These particle injections were preceded by gradual decreases and, in some energy channels, dropouts of particle fluxes. This evolution in particle fluxes is a typical preinjection behavior signaling plasma sheet thinning at these locations prior to substorm injection. One may notice that smaller injections can be seen in some energy channels just before the $\sim 1048$ UT injection, especially evident in the LANL-91 data. These small injections correspond well to the weaker magnetic disturbances on the ground prior to the 1048 UT substorm expansion onset as indicated by the CMO magnetogram and the AL index in Figure 1.

\subsection{TC-1 Observations}

[8] The plasma and magnetic field measurements from TC-1 are given in Figure 4. In each plasma flow panel, the solid trace gives the plasma flow component perpendicular to the magnetic field whereas the dotted trace gives the total plasma flow component. The fact that the dotted traces are often not noticeable in most of the interval indicates that the plasma flows were mostly perpendicular to the magnetic field in this inner region. There were very weak plasma flows perpendicular to the magnetic field at TC-1 during the early part of this time interval. TC-1 entered the tail lobe shortly after substorm onset. This transition was indicated by the absence of plasma electrons based on the data from the Plasma Electrons and Current Experiment (PEACE) [Johnstone et al., 1997]. There were frequent occurrences of cold ion beams in the tail lobe based on data from the Cluster Ion Spectrometry experiment (CIS) [Rème et al., 2001].

[9] A strong plasma flow burst occurred around $\sim 1110$ UT after TC-1 observed the recovery of the plasma density to a level similar to that before 1050 UT. This plasma flow burst was accompanied by nearly simultaneous magnetic perturbations, which will be examined in more detail later. The $B_{\mathrm{z}}$ component was close to zero before substorm onset but increased significantly starting at $\sim 1048$ UT. After the reentry of TC-1 into the hot plasma sheet at $\sim 1110$ UT during substorm expansion, the $B_{\mathrm{z}}$ component showed significant variability, similar to field fluctuations in current disruptions associated with dipolarization reported previously [e.g., Lui et al., 1988]. Therefore, current disruption phenomenon occurred at the TC-1 location. However, it is unclear whether or not the substorm onset was caused by current disruption at TC-1 or the 

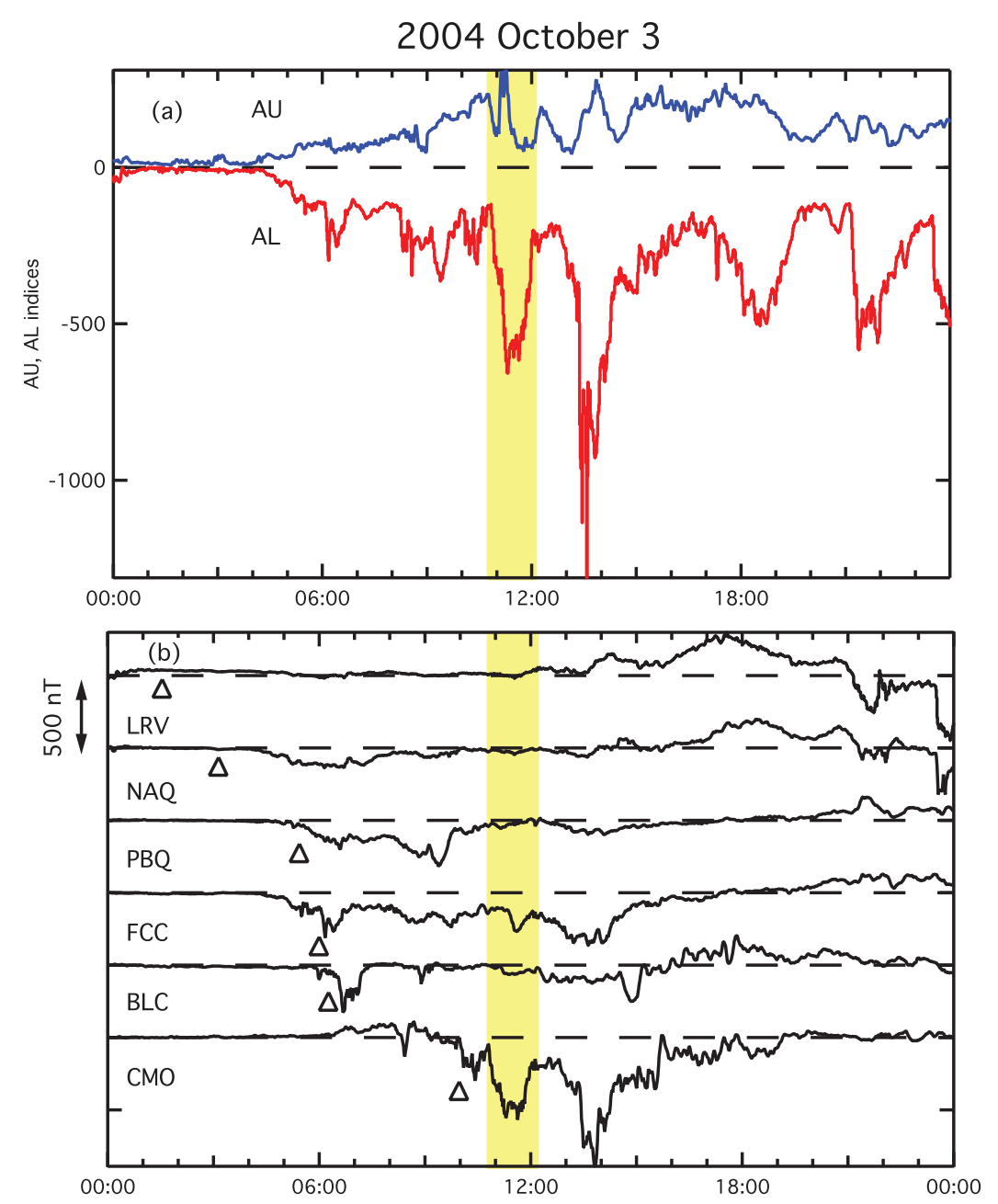

Figure 1. (a) The AU (upper trace) and AL (lower trace) indices on 2004 October 3; (b) the ground magnetic activity in terms of the north-south component from magnetic stations LRV, NAQ, PBQ, FCC, $\mathrm{BLC}$, and CMO.

disturbance at TC-1 was propagated from elsewhere or generated locally.

[10] A more expanded timescale for TC-1 data is provided in Figure 5. The dotted and solid traces in the velocity panels have the same meaning as that in Figure 4. The plasma flow burst at $\sim 1109-1111$ UT (shaded region) had a shear flow signature and was located at the interface between the cold and hot plasmas in the plasma sheet boundary layer. All three components of the plasma flow were negative first and then turned positive. In the midst of the shear flow was a significant plasma flow component along the magnetic field. A detailed examination of the velocity distribution function shows a fast ion beam with a crescent-shaped distribution in the velocity space. This shape can originate from an ion population with a fast bulk flow parallel to the magnetic field moving to a stronger magnetic field region, causing it to spread in the pitch angle space by the conservation of the first adiabatic invariant [see, e.g., Lui, 2006]. The observed feature differs from the idea of plasma flow braking in that plasma flow perpendicular to the magnetic field is considered in flow braking instead.
[11] The flow shear nature is illustrated more clearly in Figure 6 by transforming the plasma flows into a cylindrical coordinate system with radial $(\mathrm{Vr})$ and azimuthal (Vphi) components. The radial axis points to the Earth and the azimuthal axis points westward. In this coordinate system, the shear flows during $\sim 1109-1111$ UT are seen to be mainly in the azimuthal direction, like what is anticipated from plasma flows associated with an auroral arc, e.g., by magnetic field line resonance [Samson et al., 1991]. One may also notice that several increases in the $B_{\mathrm{z}}$ component and the elevation angle (Blat) of the magnetic field (Figure 6c), marked by vertical dotted lines, were not associated with any appreciable earthward plasma flow $(\mathrm{Vr})$. In fact, two of these were associated with antiearthward plasma flow instead. Since these increases were not clearly accompanied by appreciable earthward plasma flows, they are unlikely to be related to magnetic flux pileup from plasma flow braking.

[12] The presence of field-aligned current (FAC) at TC-1 is indicated by the procedure described by Volwerk et al. [1996]. The sequence of vectors in Figure 6e shows the temporal evolution of the residual magnetic field vector perpendicular to the mean magnetic field obtained from a 
(a) 2004 October 3 10:45-11:45 UT

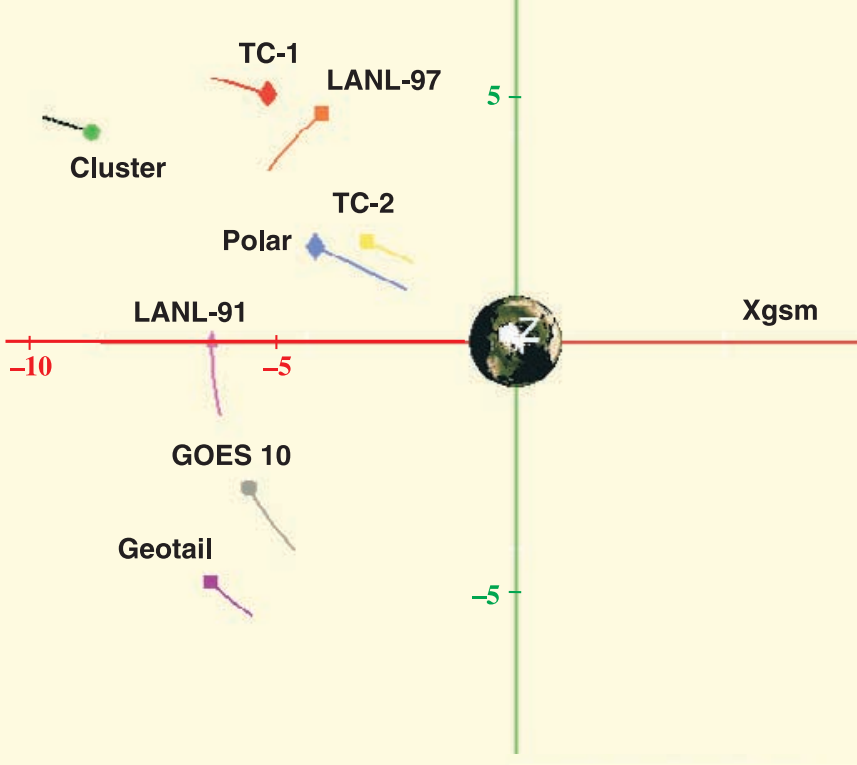

(b) 2004 October 3 10:45-11:45 UT Zgsm

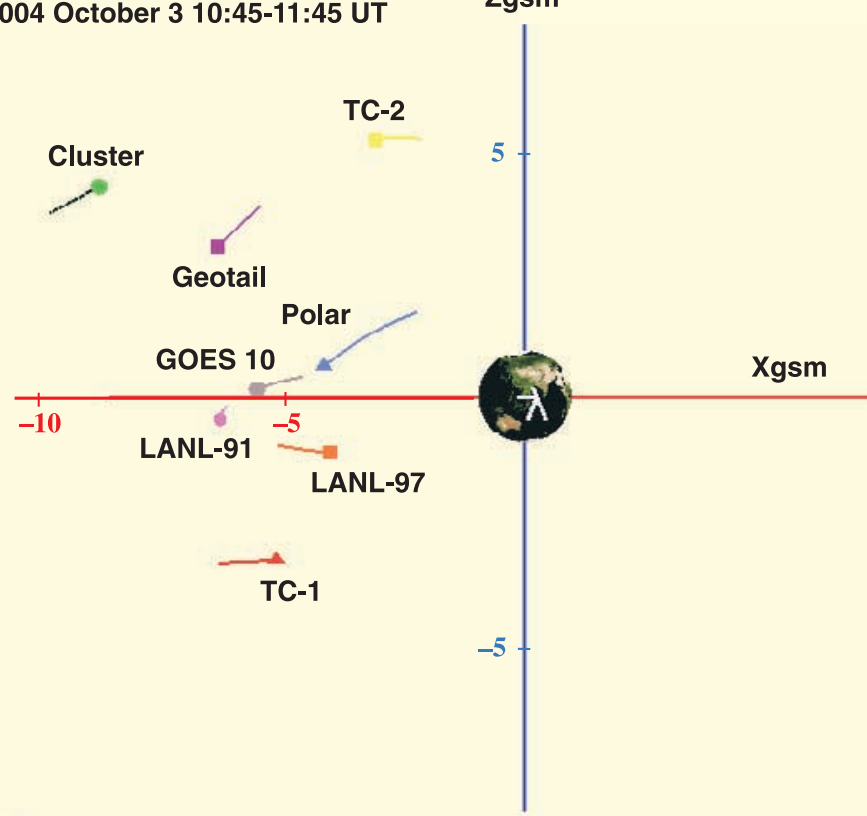

Figure 2. Projections on the (a) $X Y$-plane and (b) $X Z$-plane of satellite locations during the conjunction interval. The length of the trace associated with each satellite symbol represents the distance traveled by the satellite in an 1-h interval after 1045 UT on 3 October 2004.

low-pass filter. The mean field is pointing out of the paper. A clockwise rotation of the vectors indicates a FAC antiparallel to the mean magnetic field. For this event, there was a clockwise rotation at $\sim 1106: 30 \mathrm{UT}$, followed by an anticlockwise rotation in 1107-1108 UT coincident with the large increases in the $B_{\mathrm{z}}$ component and the elevation angle. This sequence indicates first a weak FAC antiparallel to the magnetic field (earthward from the magnetosphere to the ionosphere since TC-1 was in the southern hemisphere) followed by a stronger FAC parallel to the magnetic field (tailward from the ionosphere to the magnetosphere). Afterward, clockwise rotations were seen within the interval of $\sim 1109-1114$ UT, with the exception at $\sim 1110: 30$ UT where the vectors indicate a brief encounter of a thin current sheet with the current directed earthward. Overall, the FAC pattern is quite complicated at TC-1. 


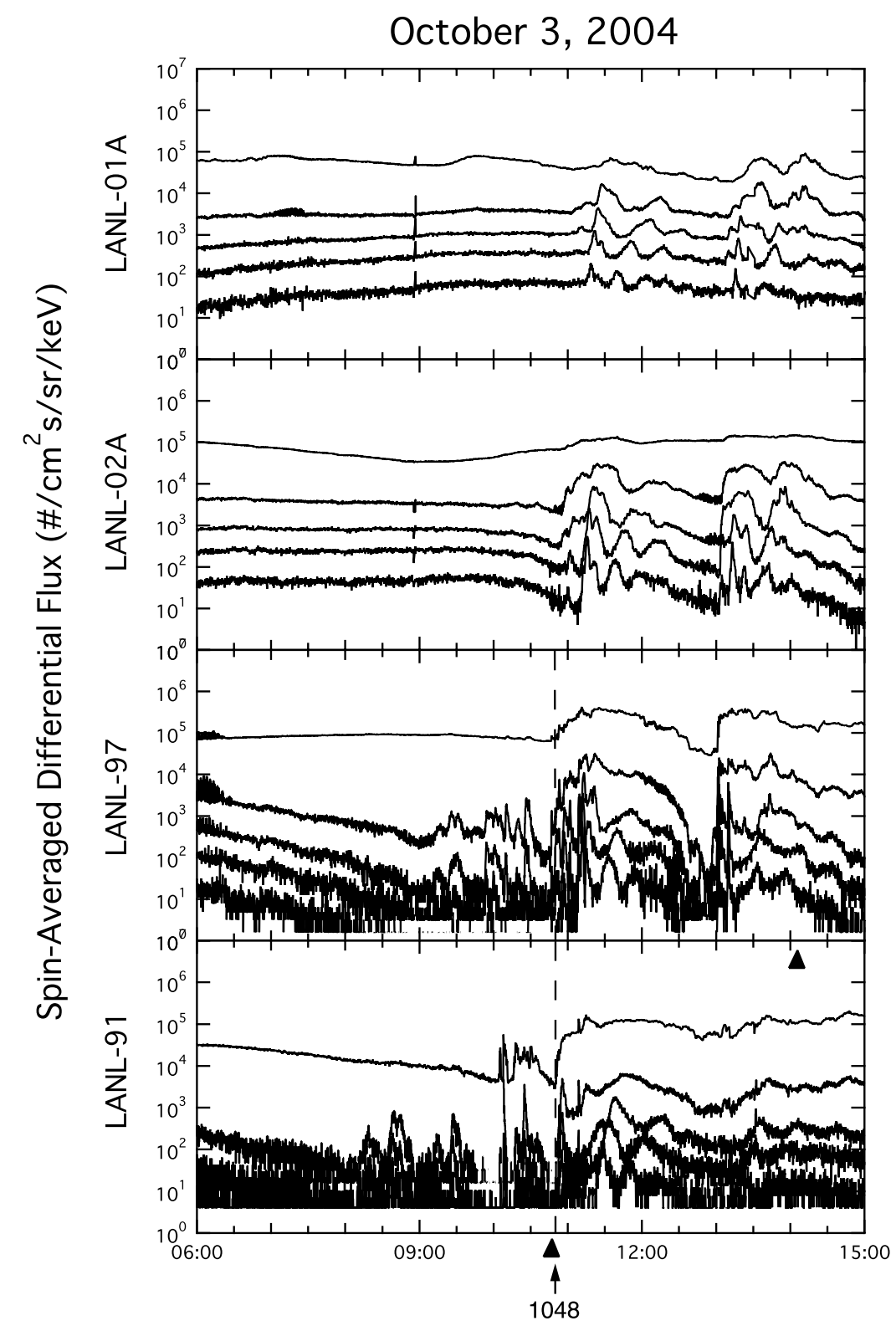

Figure 3. The intensities of energetic protons $(50-315 \mathrm{keV}$ in five energy channels) at several LANL geosynchronous satellites. The triangle underneath the LANL-97 and LANL-91 panels marks the midnight local time for that satellite.

\subsection{Cluster Observations}

[13] Measurements from the Cluster satellite SAMBA during this interval are shown in Figure 7. Since data from SAMBA are quite representative of data from the other three Cluster satellites, only SAMBA data are shown here for clarity. There was a data gap for plasma measurements in the early part of this interval. Fortunately, magnetic field data are available on all four satellites. The measured plasma parameters at Cluster had quite similar values and trends as that seen at TC-1. There was a flow burst detected at $\sim 1120$ UT by Cluster and the flow magnitude was larger than that at TC-1. Associated with this flow burst were significant magnetic disturbances just like that at TC-1.

[14] An expanded timescale plot surrounding the plasma flow burst interval is shown in Figure 8. The data show that the earthward-duskward flow burst was detected at $\sim 1120$
1121 UT. It occurred later and lasted longer than that at TC1 and had no shear flow signature. The time delay is probably due to Cluster being located further downstream than TC-1 relative to the substorm disturbance region, leading to a time delay for the substorm disturbance reaching Cluster later than TC-1. There was a significant plasma flow along the magnetic field when plasma flow was observed at Cluster. A significant increase in the $B_{\mathrm{z}}$ component occurred at $\sim 1122$ UT, marked by the vertical dotted line. The perpendicular $x$-component of plasma flow accompanying this $B_{\mathrm{z}}$ increase was weak $\left(V_{\mathrm{x}}<100 \mathrm{~km} / \mathrm{s}\right)$, preceded by several reversals in the $y$-component of plasma flow at moderate magnitudes. Therefore, similar to the situation at TC-1, this $B_{\mathrm{z}}$ increase is unlikely to be caused by the magnetic flux pileup process. 


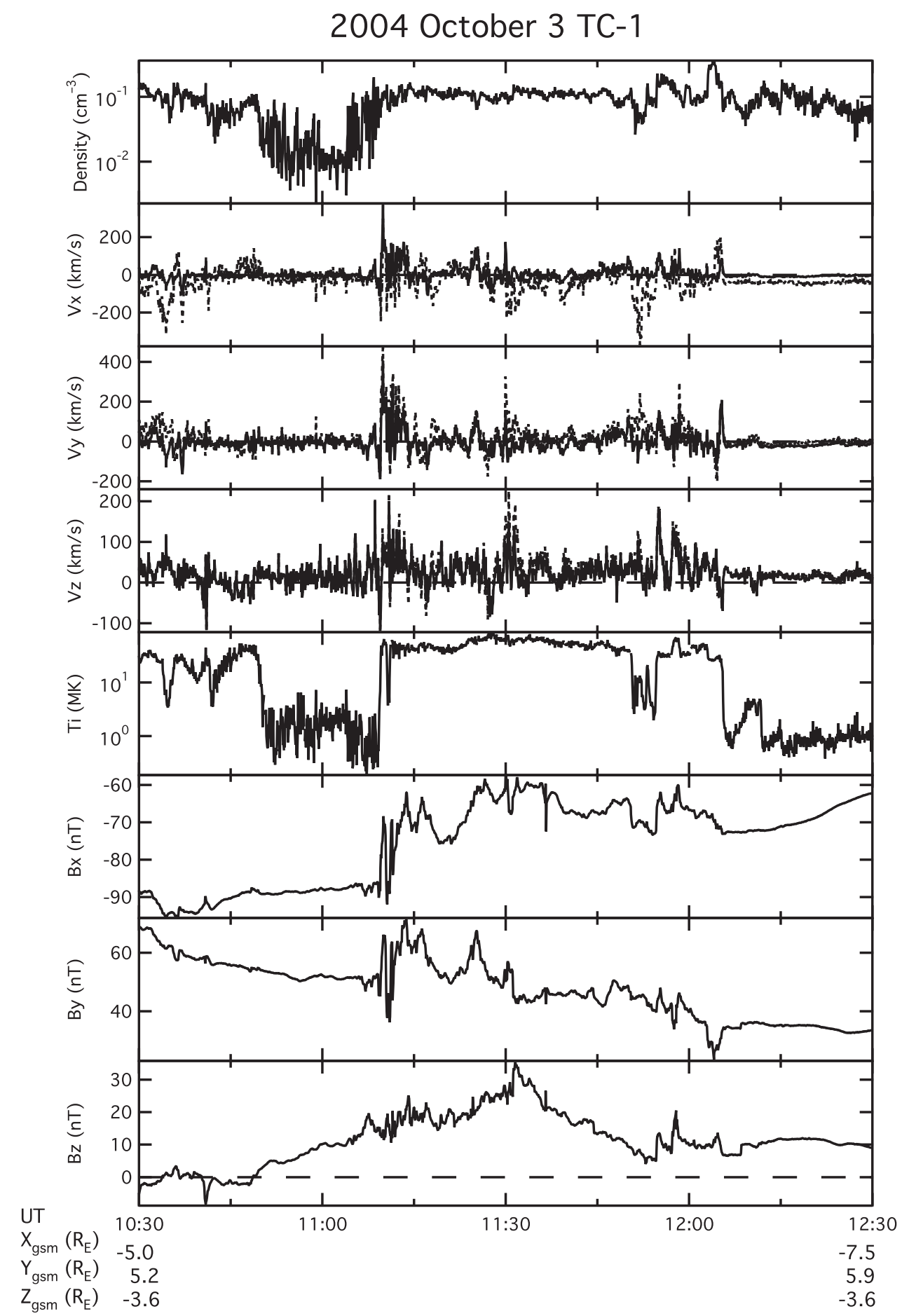

Figure 4. Plasma and magnetic field observations at TC-1.

[15] Figure 8e shows the current densities deduced by the Curlometer technique using magnetic field data from all four satellites [Dunlop et al., 1988]. The current density perpendicular to the magnetic field and the FAC density are shown separately by the solid and dotted traces, respectively. At the onset of $B_{\mathrm{z}}$ increase, which is probably related to current disruption subsequent to the one at substorm onset (note that multiple current disruption sites and onsets are envisioned in the current disruption model for substorms), the FAC is antiparallel to the magnetic field, corresponding to a current from the ionosphere to the magnetosphere. This current direction is consistent with Cluster being located at the western portion of the substorm current wedge when dipolarization reaches the Cluster location and in agreement with the premidnight location of Cluster.

\subsection{Comparison Between Cluster and TC-1 Observations}

[16] A comparison of the increases in the $B_{\mathrm{Z}}$ components between TC-1 and the Cluster satellite is given in Figure 9, 


\section{October 3 TC-1}

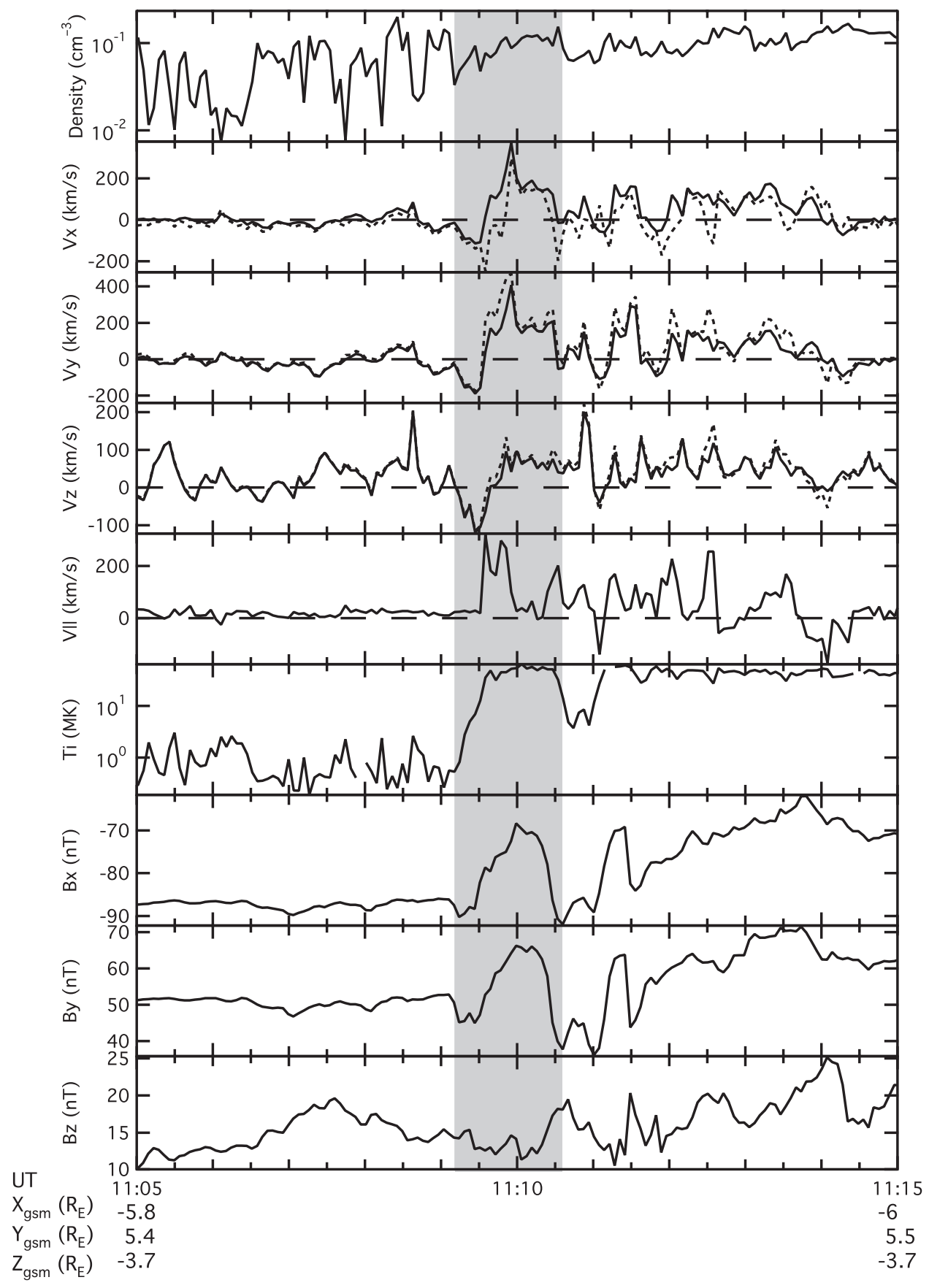

Figure 5. An enlarged timescale of observations at TC-1 to show the presence of plasma flow shear, flow burst along the magnetic field, and several magnetic field dipolarizations.

which also shows the separation distances between the four Cluster satellites in the $X Y$ - and $Y Z$-planes. A distinct increase in the $B_{\mathrm{z}}$ component was seen by $\mathrm{TC}-1$ at $\sim 1048$ UT. The plot shows that TC-1 detected the increase $\sim 1.5$ min before the Cluster satellite. An operational definition for dipolarization used here is a significant increase of $B_{\mathrm{z}}$ exceeding its variation prior to detection of substorm activity at the satellite. The gradual $B_{\mathrm{z}}$ increase at Cluster in the interval $\sim 1046-1049$ UT is therefore not considered to be dipolarization because its variability was within the $B_{\mathrm{z}}$ values well before the substorm onset (e.g., 1035-1042 UT). Since TC-1 was earthward of Cluster, this time sequence suggests that the substorm activity was initiated closer to the Earth than the Cluster location. The onset time being earlier at TC-1 is unlikely caused by substorm activity spreading dawnward from the premidnight to midnight hours because both Los Alamos satellites detected substorm injections nearly simultaneously. In fact, 
2004 October 3 TC-1

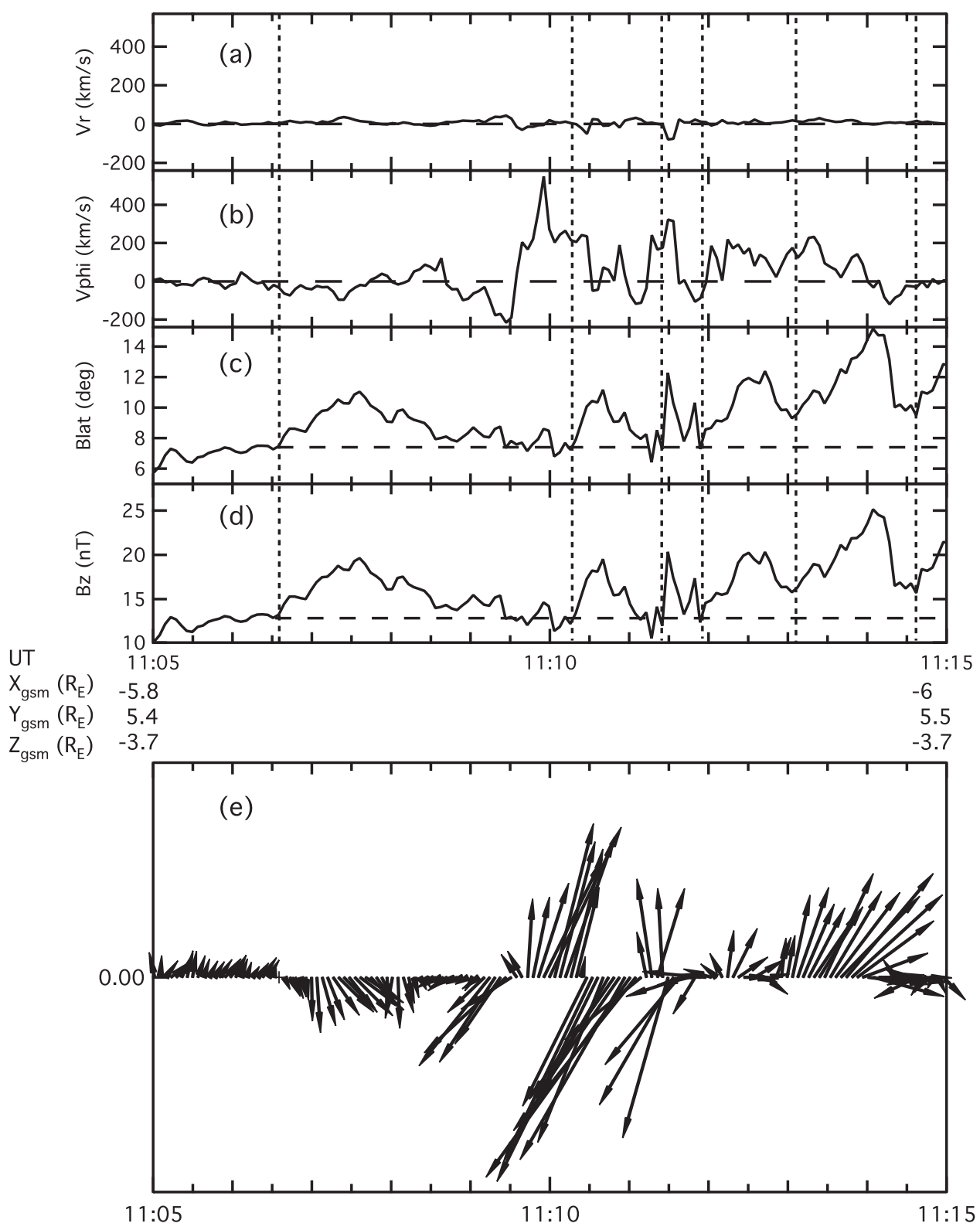

Figure 6. (a-d) Plasma flow and magnetic field data from TC-1 to show the signature of flow shear and the lack of association between dipolarization and earthward plasma flow; (e) vectors showing the residual magnetic field perpendicular to the mean magnetic field direction to examine the field-aligned currents.

LANL-97 was furthest away from the midnight meridian than both TC-1 and Cluster. This indicates that there was not much time delay in substorm disturbance from the nearmidnight MLT of LANL-91 to the premidnight MLT of LANL-97 and that the delay in Cluster is not due to local time spreading of substorm disturbance.

[17] Detailed timing analysis of the $B_{\mathrm{z}}$ increase among the four Cluster satellites with the high-time resolution data indicates that $\mathrm{C} 1$ (RUMBA) and $\mathrm{C} 4$ (TANGO) lagged slightly behind C2 (SALSA) and C3. From their relative positions, one can conclude that the time delay for $\mathrm{C} 1$ is due to expansion in the positive $Z_{\mathrm{gsm}}$ direction and the delay for
C4 is due to tailward expansion along the $X_{\mathrm{gsm}}$ axis. Since the satellites were north of the equatorial plane and the observed $B_{\mathrm{x}}$ component was positive, the $Z_{\mathrm{gsm}}$ expansion is consistent with the $B_{\mathrm{z}}$ increase propagating away from the equatorial plane. The tailward $X_{\mathrm{gsm}}$ expansion is consistent with the $B_{\mathrm{z}}$ increase propagating tailward, in agreement with the increase in the $B_{\mathrm{z}}$ being observed earlier at TC-1.

[18] It may be noted that the $B_{\mathrm{z}}$ component for TC-1 and Cluster satellites was negative at the start of the interval shown. This is due to two factors. The first factor is the proximity of the satellites to the Earth that makes the magnetic field orientation affected appreciably by 


\section{October 3 CLUSTER}

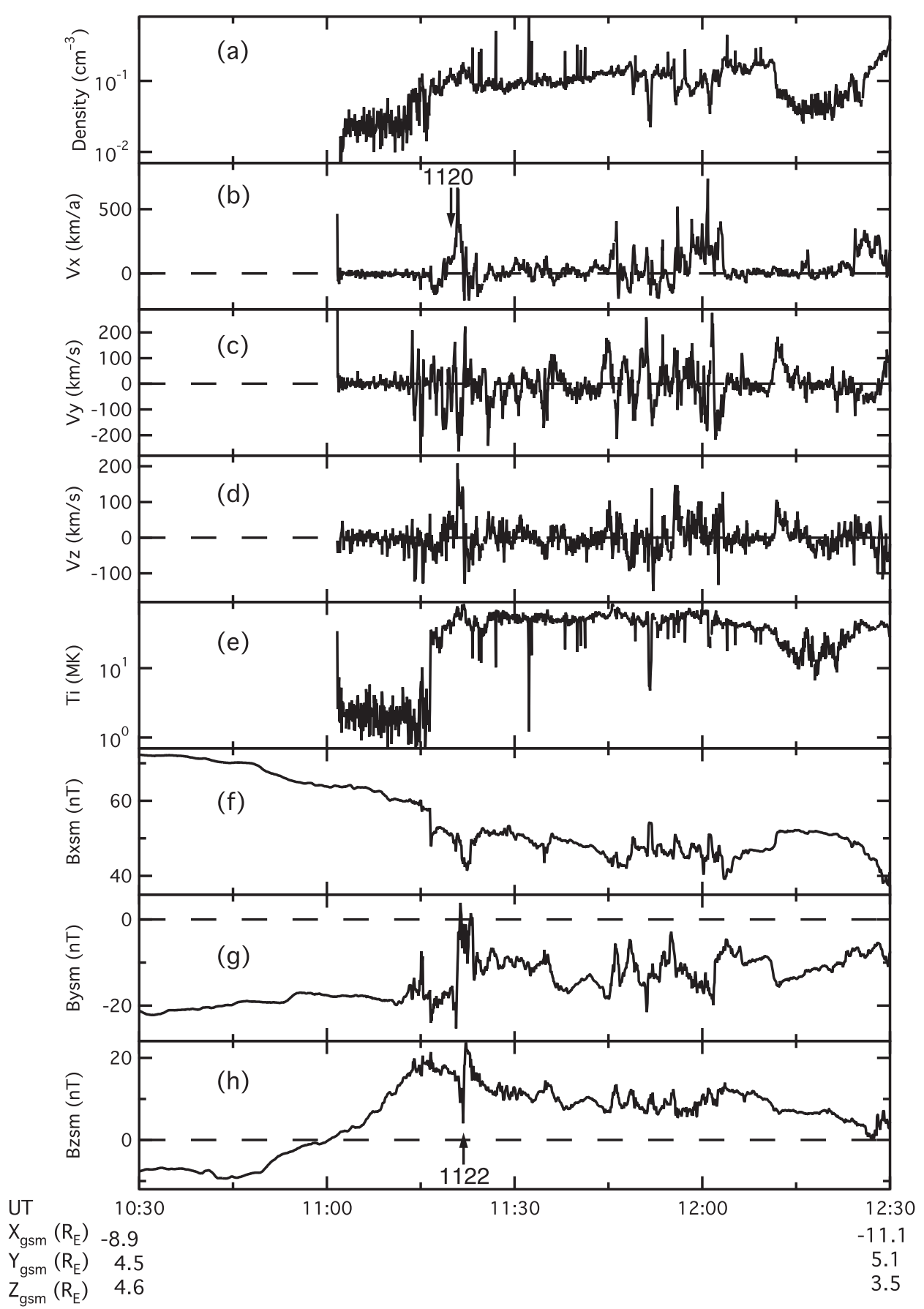

Figure 7. Plasma and magnetic field observations at the Cluster satellite (only $\mathrm{C} 3$ data shown). Plasma parameters are from CIS/HIA [Rème et al., 2001]. The magnetic field measurements are from FGM [Balogh et al., 2001].

the Earth's dipole field. The second factor is the necking down of the near-Earth plasma sheet during substorm growth and early expansion phases, causing the magnetic field orientation dipping southward for satellites located tailward of the location where the plasma sheet is thinnest. However, the transient sharp decrease in the $B_{\mathrm{z}}$ component at TC-1 near $\sim 1041$ UT cannot be explained by these two factors and may be related to a late response of the previous substorm activity that started at about 0959 UT (see Figure 1).

\subsection{Geotail Observations}

[19] Geotail data during this period are given in Figure 10. Geotail was in the central plasma sheet at the start of the 


\section{October 3 CLUSTER}

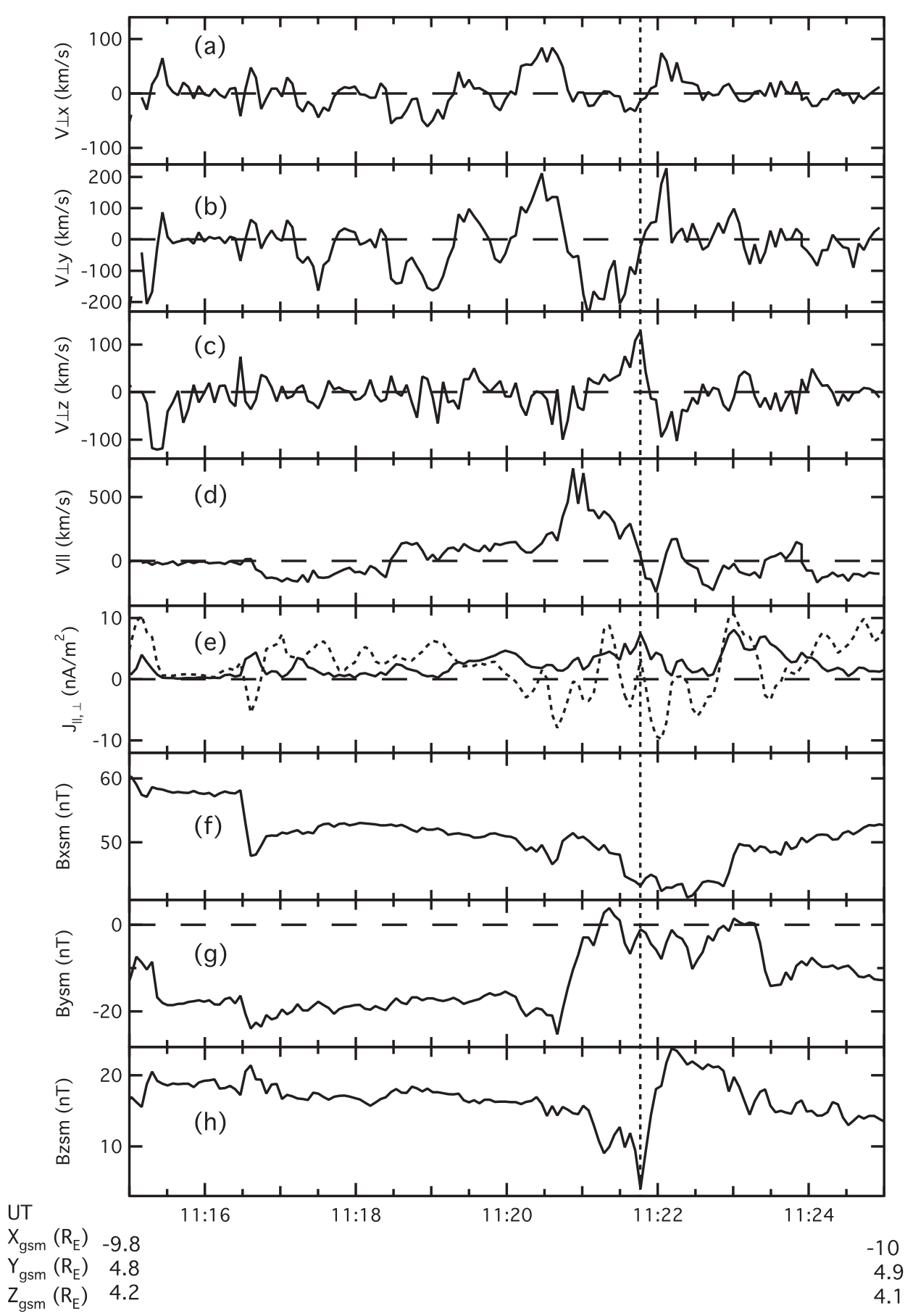

Figure 8. An enlarged timescale of observations at Cluster satellite (only $\mathrm{C} 3$ data shown) to show the occurrence of a significant magnetic field dipolarization.

interval. During the interval of $\sim 1035-1155$ UT, the plasma density became low from plasma sheet thinning, indicative of plasma sheet boundary entry accompanied by a slight decrease in the magnetic field elevation angle. There was a small increase in number density during $\sim 1107-$ $1130 \mathrm{UT}$, corresponding to the time interval when the $B_{\mathrm{x}}$ component was depressed in comparison with values at other times. The anisotropy of $67 \mathrm{keV}$ energetic ions (which is a sensitive indicator of plasma flow) and the plasma flow were small and mainly perpendicular to the magnetic field. A small but noticeable increase in the $V_{\mathrm{x}}$ component to $>100 \mathrm{~km} / \mathrm{s}$ was observed late in the substorm recovery phase at $\sim 1157$ UT. It was accompanied by a significant increase in number density and noticeable decreases in the $B_{\mathrm{x}}$ and $B_{\mathrm{z}}$ components indicative of reentry to the central plasma sheet. However, the recovered central plasma sheet 


\section{October 31050 UT CLUSTER}
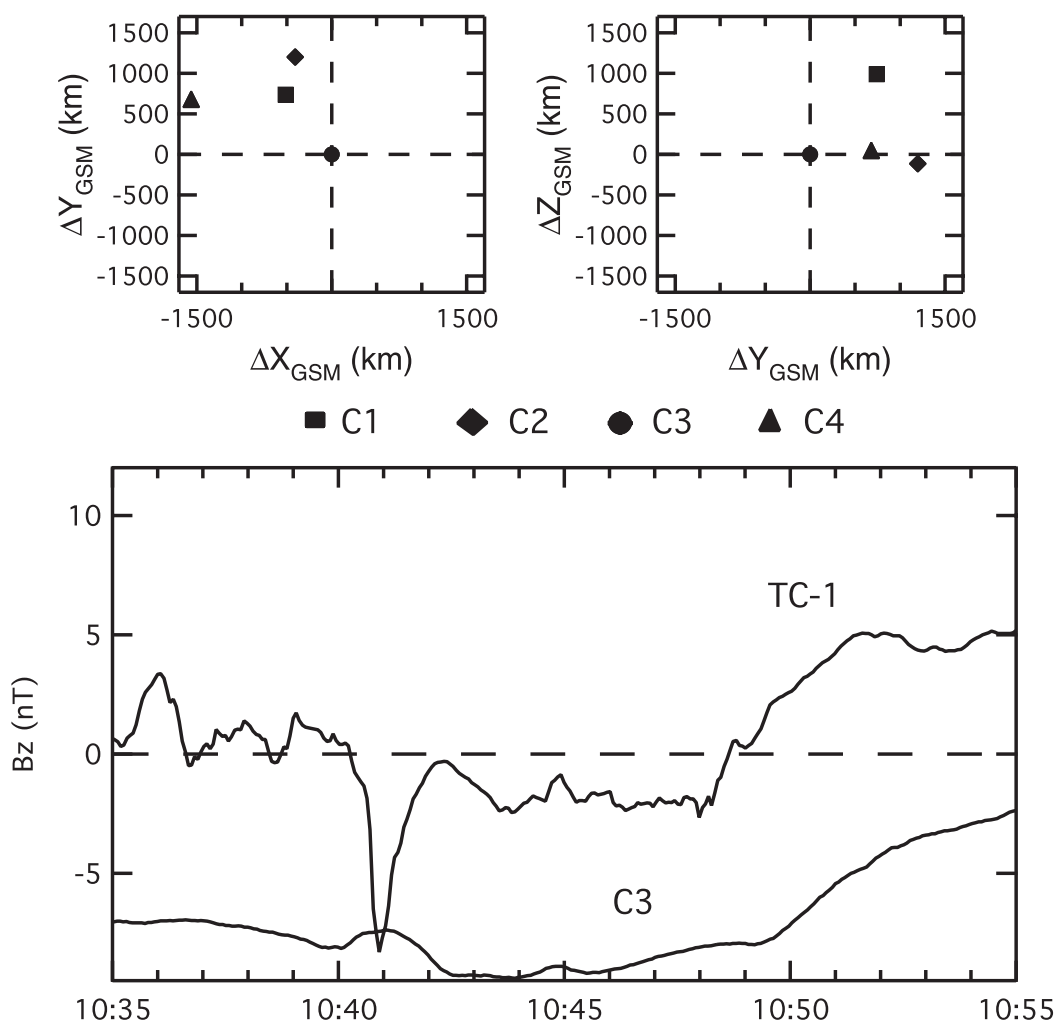

Figure 9. Comparison between TC-1 and Cluster measurements on the increase in the $B_{\mathrm{z}}$ component that occurred nearly simultaneously with the substorm injections at the geosynchronous altitude. The relative locations of the four Cluster satellites are also shown.

was at a lower temperature than before expansion onset, indicated also by the low level of energetic ion flux.

\subsection{GOES-10 Observations}

[20] The magnetic field data from GOES-10 and Polar are shown in Figures 11a-11d. GOES-10, located at postmidnight MLT, detected noticeable increases in the elevation angle of the magnetic field (Figure 11a) and the $B_{\mathrm{z}}$ component (Figure 11d) starting at $\sim 1044$ UT. Further increases in these field quantities occurred at $\sim 1053 \mathrm{UT}$, marked by the vertical dotted line, and was accompanied by a sharp decrease in the $B_{\mathrm{x}}$ component. These changes indicate GOES-10 encountering an energetic particle population in association with dipolarization. A positive $B_{\mathrm{y}}$ perturbation was associated with this encounter, suggesting that this magnetic perturbation arises from crossing a pair of current sheets as GOES-10 encountered the energetic particle population. The sign of the $B_{\mathrm{y}}$ perturbation is indicative of the outer sheet carrying FAC down to the ionosphere and the inner sheet carrying FAC up to the magnetosphere, as illustrated in Figure 12a. The current direction in the outer current layer is consistent with the current direction for the eastern portion of the substorm current wedge while the current direction in the inner current layer is consistent with the direction for a meridional closure of FAC. The existence of meridional closures of FAC associated with dipolarization is also demonstrated recently by M. Volwerk et al.
(Magnetotail dipolarization and associated current systems observed by Cluster and Double Star, submitted to Journal of Geophysical Research, 2008) from the analysis of a substorm event with data from the Cluster and TC-1 satellites.

\subsection{Polar Observations}

[21] Polar magnetic field panels in Figures 11e-11g show the difference between the observed magnetic field and the field values from the IGRF95 plus the magnetic field model of Tsyganenko [1995]. The $B_{\mathrm{x}}$ component without subtraction of the magnetic field from the model was positive, indicating that Polar was north of the equatorial plane (see also Figure 2b). There was an overall gradual increase in the $B_{\mathrm{z}}$ component relative to the field model starting at $\sim 1038$ UT. However, there was no sharp decrease in the $B_{\mathrm{x}}$ component similar to the GOES-10 data that may be used as an indication for the arrival of an energetic particle population. Nevertheless, if one considers the decrease in the $B_{\mathrm{x}}$ component starting at $\sim 1049$ UT as due to a more gradual effect from the arrival of an energetic particle population, then the $B_{\mathrm{y}}$ perturbation was negative. Similar to the interpretation given for GOES-10, this change can be due to an encounter of a pair of current sheets, except that the current directions are opposite, i.e., the outer current layer has FAC directed from the ionosphere to the magneto- 


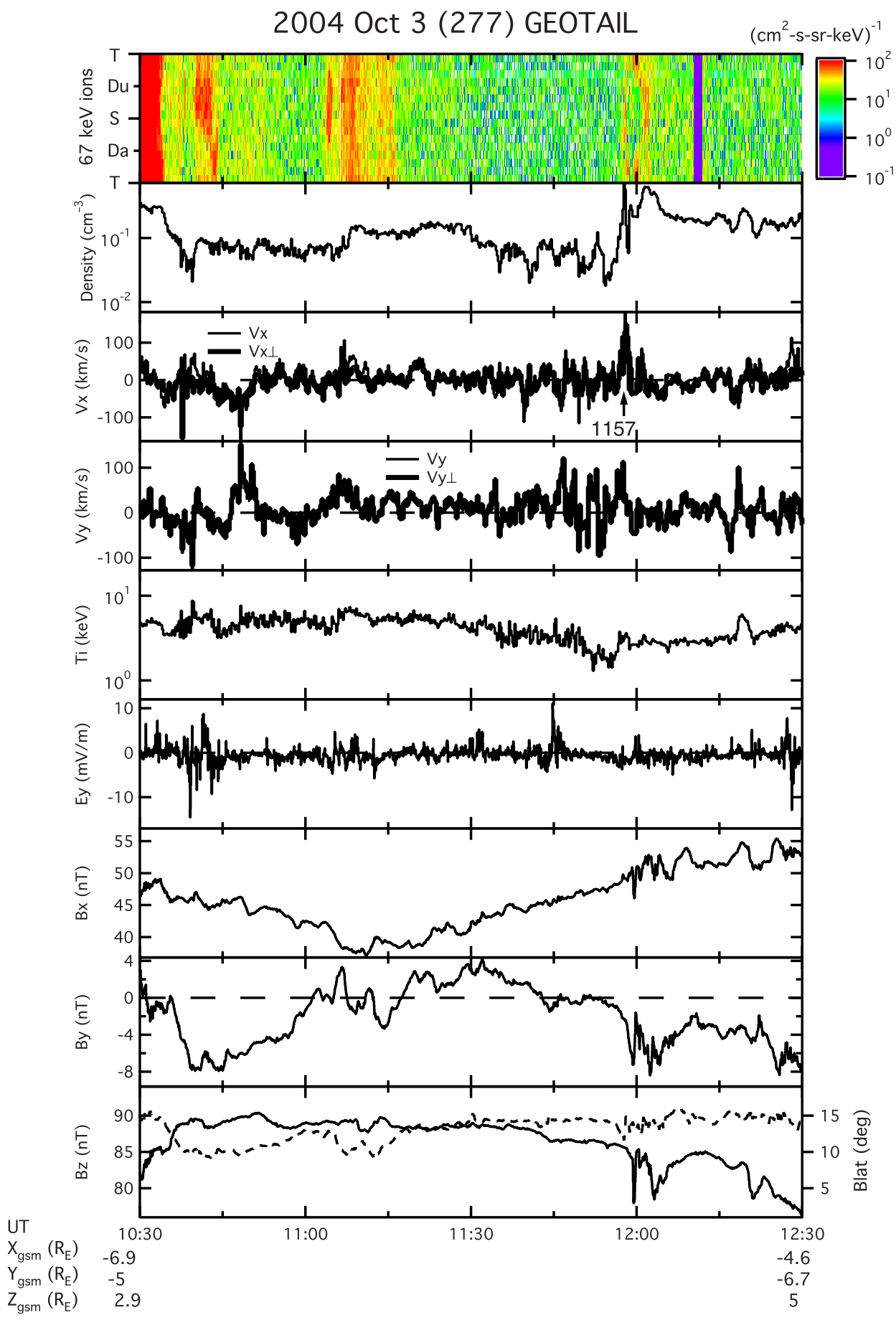

Figure 10. Geotail data from the Energetic particle and Ion Composition (EPIC) instrument [Williams et al., 1994], Low Energy Particle (LEP) experiment [Mukai et al., 1994], Electric Field (EFD) experiment [Tsuruda et al., 1994], and magnetic field (MGF) instrument for the substorm interval. The labels T, Du, S, Da in the $67 \mathrm{keV}$ ion anisotropy panel indicate tailward, duskward, sunward, and dawnward ion motions, respectively. The magnetic field elevation angle (Blat) is given in the bottom panel by the dashed trace.

sphere (see Figure 12a). This current direction is consistent with the western portion of the substorm current wedge. The inner current layer is then a part of the meridional closure of FAC at this western portion.
2.10. Substorm Reconfiguration in the Near-Earth Magnetotail

[22] One may construct the time evolution of magnetic field configuration and plasma sheet boundary motion 


\section{October 3 GOES-10/POLAR}
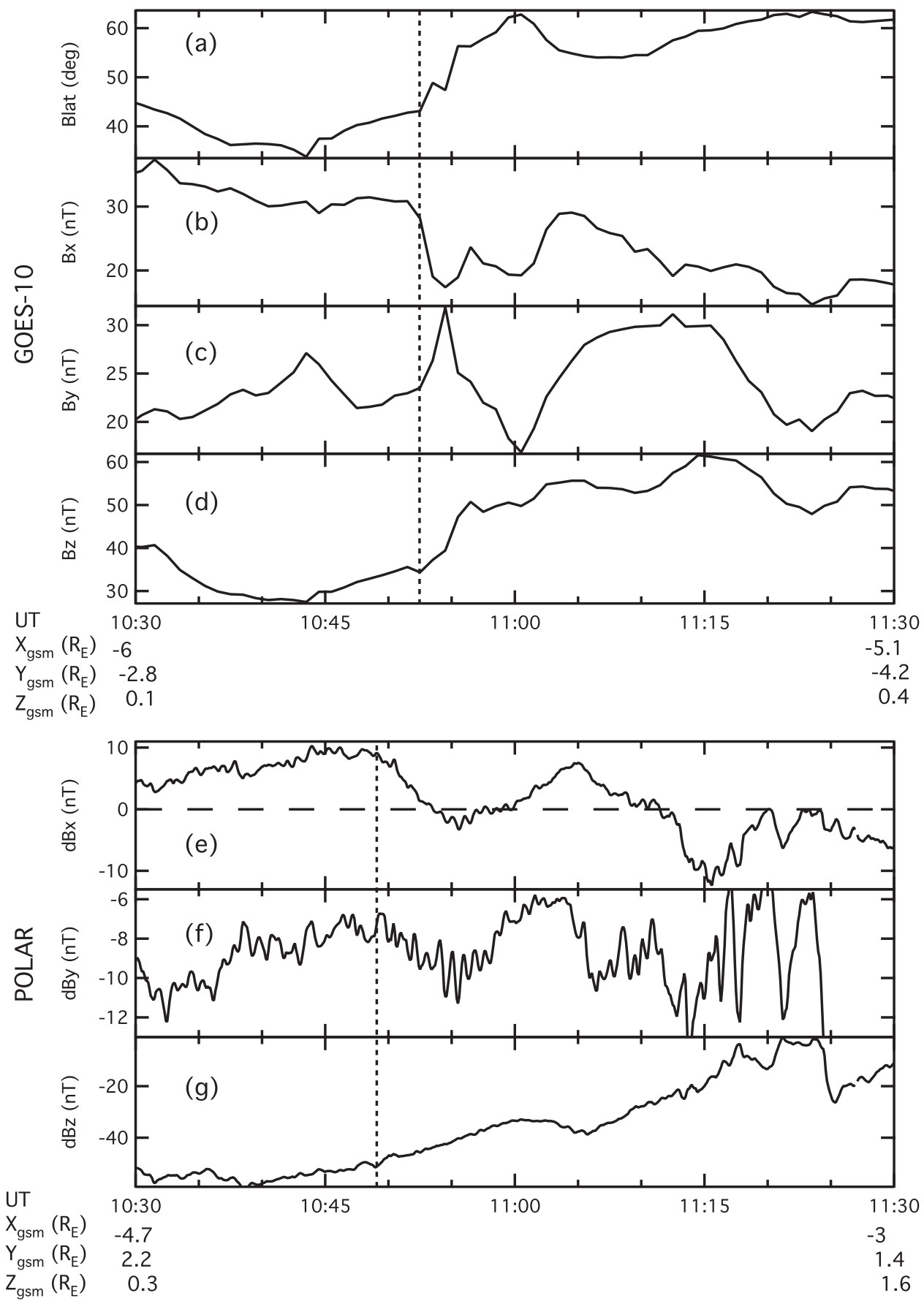

Figure 11. Magnetic field measurements from GOES-10 and Polar satellites. The $B_{\mathrm{y}}$ perturbations from these satellites suggest encountering of a pair of field-aligned current sheets. The directions of fieldaligned currents in the outer layers at postmidnight and premidnight local times are consistent with the directions of field-aligned currents for the substorm current wedge.

during this substorm based on the collective observations of these satellites. Figure 12b shows schematic diagrams to illustrate this temporal development in four stages. The satellite locations are not precise and only used to represent their positions relative to the plasma sheet boundary. Also, they are not all in the same meridian plane. The arrows at
GT, CL, and T1 denote the magnetic field orientations at these locations. During the substorm growth phase (Figure 12b, top left), the plasma sheet boundary layer (PSBL) reaches TC-1 location but not Cluster location due to plasma sheet thinning in the transition region. The magnetic field elevation angles at both Cluster and TC-1 are 
(a)

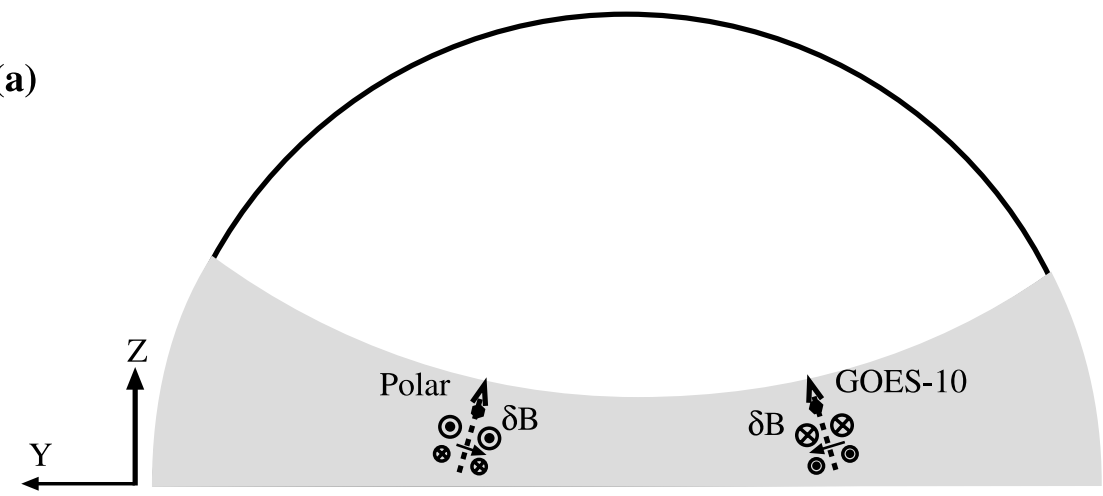

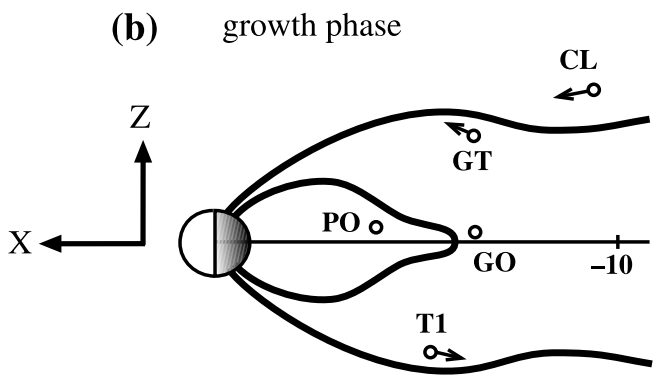

early expansion phase

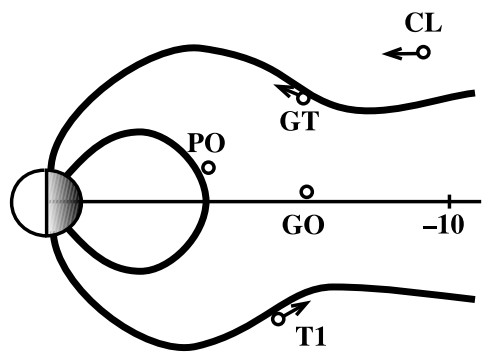

expansion onset

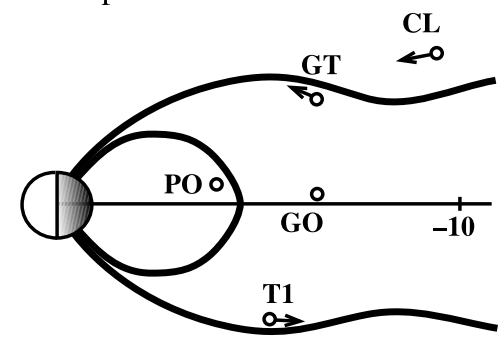

late expansion phase

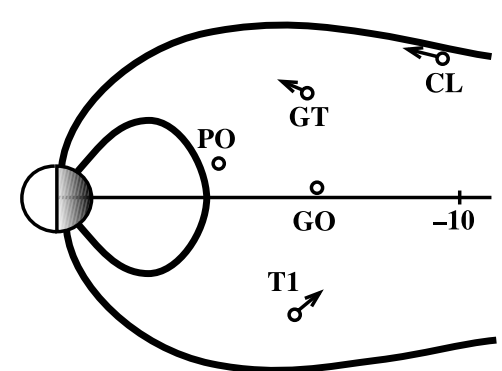

Figure 12. (a) A schematic diagram to illustrate the magnetic perturbations associated with a pair of current sheets in the dawn and dusk portions of the near-Earth magnetotail. The solid arrows indicate the magnetic perturbations. The circles with embedded dots and crosses represent field-aligned currents flowing out and into the plane, respectively. The size of the circles represents the current strength. The dotted arrow associated with each pair of current sheets indicates the path of the current sheets across the satellite. (b) Schematic diagrams to illustrate the temporal evolution of the magnetic field configuration and plasma sheet boundary motion during this substorm projected on the XZ-plane. The satellite symbols PO, GT, CL, GO, and T1 denote Polar, Geotail, Cluster, GOES-10, and TC-1, respectively.

slightly negative. Geotail approaches the PSBL during this phase. At substorm expansion onset (Figure 12b, top right), substorm injection reaches the geosynchronous altitude. The magnetic field elevation angles at both TC-1 and Cluster increase but that at Cluster remains negative. A slight increase in magnetic field elevation angle occurs also at Geotail. Shortly after substorm onset (Figure 12b, bottom left), plasma sheet thinning causes TC-1 to exit the PSBL while Cluster remains in the tail lobe. GOES-10 and Polar detect the substorm current system consisting of both azimuthal closure (substorm current wedge system) and meridional closure of FACs. Geotail remains in the lowdensity PSBL. Well into the substorm expansion phase (Figure 12b, bottom right), plasma sheet expansion reaches TC-1 and Cluster. A slight plasma sheet expansion indicated by a slight increase in the plasma density occurs at Geotail. Geotail reenters the central plasma sheet only in the late substorm recovery phase.

\section{Summary and Discussion}

\subsection{Unique Multipoint Near-Earth Substorm Observations}

[23] We have examined one substorm event on 3 October 2004 with conjunction of eleven satellites in the near-Earth magnetotail $\left(X_{\mathrm{GSM}}>-10 R_{\mathrm{E}}\right)$. In terms of usable data for analysis, the conjunction consists of ten satellites, namely, four Cluster satellites, one Double Star satellite, two Los Alamos geosynchronous satellites, Polar, GOES-10, and Geotail. This opportunity offers an excellent chance to examine closely the temporal sequence of substorm 
disturbances in the near-Earth magnetotail and the relationship between plasma flow bursts and magnetic field changes near the transition region of magnetic field configuration from dipole to tail-like. To our knowledge, this report is the first example with so many satellites in the near-Earth nightside magnetosphere $\left(X_{\mathrm{GSM}}>-10 R_{\mathrm{E}}\right)$ for a substorm study. The abundance of multipoint measurements from this fortuitous situation allows less ambiguity in determining the near-Earth substorm features.

\subsection{Plasma Flow Shear in the Near-Earth Magnetotail}

[24] TC-1 observed a plasma flow shear signature during this substorm interval. The plasma flow shear appears to be in the azimuthal direction. This plasma flow shear may be related to plasma flows (convection) being primarily tangential to an auroral arc as indicated by ground observations reported previously [e.g., Samson et al., 1996; Bristow et al., 2003]. An accelerated earthward ion beam along the magnetic field occurred at the reversal of the plasma flow within this flow shear. Such substorm features in the nearEarth magnetosphere $\left(X_{\mathrm{GSM}}>-6 R_{\mathrm{E}}\right)$ have never been reported before.

\subsection{Meridional Closure Current System}

[25] The dawn-dusk magnetic perturbations observed at GOES-10 and Polar are consistent with the coexistence of both current types discussed by Boström [1964] for the substorm current system, i.e., the type 1 current system commonly known as the substorm current wedge (azimuthal closure of field-aligned currents) as well as the type 2 current system (meridional closure of field-aligned currents). The existence of the type 2 current system in substorms has been revealed by other satellite observations [Lopez et al., 1990; Volwerk et al., submitted reference, 2008], ground magnetic observations [Kamide et al., 1994], SuperDarn convection observations [Liang et al., 2006], and particle simulation [Pritchett and Coroniti, 2002]. The dynamo associated with the type 2 current system has also been discussed in terms of a plasma instability that can produce both type 1 and type 2 current systems during substorms [Lui and Kamide, 2003]. One unique aspect of the dawn-dusk magnetic perturbations reported here are the simultaneous observations at both the dusk and dawn portions of the substorm activity region. Such simultaneous observations in the magnetosphere have not been reported before.

\subsection{Evidence of the Near-Earth Initiation Model}

[26] Analysis of observations in this event indicates that this substorm was initiated close to the Earth, as suggested by the near-Earth initiation model for substorms. This conclusion comes from the following consideration. Substorm disturbances were observed nearly simultaneously at the geosynchronous altitude over a wide local time sector that covers the locations of TC- 1 and Cluster satellites. The substorm activity at TC-1 located earthward of Cluster and at nearly the same $Y_{\mathrm{GSM}}$ coordinate as Cluster $\left(<1 \quad R_{\mathrm{E}}\right.$ apart) observed the substorm activity (current disruption and dipolarization) earlier than Cluster by $\sim 1.5 \mathrm{~min}$. This temporal sequence and the lack of earthward plasma flow associated with dipolarization strongly indicate that the substorm disturbance was initiated near the geosynchronous altitude and subsequently spread to further downstream distances, unconnected to plasma flow braking.

[27] This result is consistent with some previous findings that indicate dipolarization in the near-Earth magnetotail is caused by a non-MHD process and is unrelated to magnetic flux pileup [e.g., Lui et al., 1999; Shiokawa et al., 2005; Ohtani et al., 2006]. For this issue, it is important to note that magnetic flux is carried by plasma flow in the MHD approach. This condition is the result of the frozen-in condition in the MHD formulation. Therefore, if there is no plasma flow entering into a region, then there is no magnetic flux carried into that region. For example, if plasma flow brakes before reaching that region, there will not be any increase in magnetic flux there. In fact, if dipolarization occurs over a broad region in the magnetosphere and plasma flows only occur in some narrow channels, then the dipolarization cannot be accounted for by plasma flows from these narrow channels bringing magnetic flux into the broad dipolarization region of the magnetosphere. On the other hand, the current disruption model separates field disturbance from plasma flow since current disruption is a non-MHD process. Therefore, dipolarization will propagate through the medium by waves. Plasma flow generally does not coincide with the wave velocity. As a result, dipolarization does not necessarily link with plasma flow occurrence even though current disruption can lead to force imbalance and generate plasma flow.

\subsection{Inference From High-Latitude Magnetotail Observations}

[28] High-latitude magnetotail observations have been modeled previously to infer the onset location of current disruption and its subsequent tailward propagation during substorms [Jacquey et al., 1991, 1993; Ohtani et al., 1992]. Both Cluster and TC-1 were in the high-latitude magnetotail at the substorm onset time. The approach used in these previous studies of high-latitude magnetotail can be applied to this event. At Cluster location, the $B_{\mathrm{x}}$ component started to decrease at $1048 \mathrm{UT}$, i.e., about $1.5 \mathrm{~min}$ before the onset of the $B_{\mathrm{z}}$ increase at Cluster. Since there was no significant decrease of solar wind dynamic pressure at that time from the Wind observation (with the solar wind propagation time taken into account), the $B_{\mathrm{x}}$ decrease indicates that the energy release related to current disruption started at 1048 UT. The $B_{\mathrm{z}}$ increase indicates that the current disruption front reached the downstream distance of the Cluster location about $1.5 \mathrm{~min}$ later. At TC-1, the dipolarization $\left(B_{\mathrm{z}}\right.$ increase) onset coincided with the substorm onset observed from the ground at $1048 \mathrm{UT}$. No decrease of $B_{\mathrm{x}}$ was observed at TC-1 due to its exit to the tail lobe such that the decrease in $B_{\mathrm{x}}$ from current reduction was masked by the increase in $B_{\mathrm{x}}$ from entry to the tail lobe. This plasma sheet thinning is probably related to the associated inductive electric field at substorms [e.g., Sauvaud et al., 1984]. The spatial separation between TC-1 and Cluster together with the time delay of dipolarization onsets between these locations gives a tailward propagation speed of dipolarization at $\sim 300 \mathrm{~km} / \mathrm{s}$. This estimate is in very good agreement with the speed inferred from previous studies [Jacquey et al., 1991, 1993; Ohtani et al., 1992]. 


\subsection{Other Potential Deficiencies in the Midtail Initiation Model}

[29] There is another relevant observation related to the distinction between the midtail initiation model and the near-Earth initiation model. From a summary of the ICS-5 session on the interpretation of auroral observations in terms of plasma sheet dynamics, Lui [2000] pointed out several substorm features that are difficult to explain by the midtail initiation model. In particular, it is well known that multiple parallel auroral arcs are often seen from ground all-sky or TV cameras prior to a substorm onset and the breakup arc is typically the most equatorward one. These detailed groundbased observations with high spatial and intensity resolutions indicate that the parallel arcs poleward of the breakup arc are undisturbed prior to onset. This poses the following problem for the midtail initiation model. If the onset arc were due to intrusion of plasma flow from the midtail, how could the plasma flow skip disturbing the parallel auroral arcs poleward of the onset arc since auroral arcs are recognized to be on magnetic field lines close to the nearEarth region well earthward of the midtail region?

[30] Another noteworthy point is that for the midtail initiation model, substorm expansion in local time is mainly associated with a dawn-dusk extension of the midtail magnetic reconnection region. Under this scenario, dipolarization in any local time would be associated with significant earthward plasma flow and less significant azimuthal plasma flow. The TC-1 observation, however, shows the opposite characteristics, i.e., significant azimuthal plasma flow and almost negligible earthward plasma flow.

[31] Acknowledgments. This work was supported in part by the NSF grant ATM-0630912 and NASA grants NNG04G128G and NNX07AQ50G to the Johns Hopkins University Applied Physics Laboratory. ML and AG are supported by STFC grant PP/E000983. We are grateful to the International Space Science Institute in Bern, Switzerland, and its staff for their hospitality and financial support for the workshop.

[32] Zuyin Pu thanks Christian Jacquey and another reviewer for their assistance in evaluating this paper.

\section{References}

Akasofu, S.-I. (1964), The development of the auroral substorm, Planet. Space Sci., 12, 273-282, doi:10.1016/0032-0633(64)90151-5.

Angelopoulos, V., et al. (1996), Multipoint analysis of a bursty bulk flow event on April 11, 1985, J. Geophys. Res., 101, 4967-4990, doi:10.1029/ 95JA02722.

Balogh, A., et al. (2001), The Cluster magnetic field investigation: overview of in-flight performance and initial results, Ann. Geophys., 19, $1207-1217$

Birn, J., et al. (1999), Flow braking and the substorm current wedge, J. Geophys. Res., 104, 19,895-19,903, doi:10.1029/1999JA900173.

Boström, R. (1964), A model of the auroral electrojets, J. Geophys. Res., 69, 4983-4999, doi:10.1029/JZ069i023p04983.

Bristow, W. A., et al. (2003), Detailed analysis of substorm observations using SuperDARN, UVI, ground-based magnetometers, and all-sky imagers, J. Geophys. Res., 108(A3), 1124, doi:10.1029/2002JA009242.

Cheng, C. Z., and A. T. Y. Lui (1998), Kinetic ballooning instability for substorm onset and current disruption observed by AMPTE/CCE, Geophys. Res. Lett., 25, 4091-4094, doi:10.1029/1998GL900093.

Dunlop, M. W., et al. (1988), Analysis of multipoint magnetometer data, Adv. Space Res., 8, 273-277, doi:10.1016/0273-1177(88)90141-X.

Erickson, G. M. (1995), Substorm theories: United they stand, divided they fall, Rev. Geophys., 33, 685-692, doi:10.1029/95RG00398.

Erickson, G. M., et al. (2000), Electromagnetics of substorm onsets in the near-geosynchronous plasma sheet, J. Geophys. Res., 105, 25,26525,290, doi:10.1029/1999JA000424.

Haerendel, G. (1992), Disruption, ballooning or auroral avalanche, in Proceedings of the First International Conference on Substorms, Kiruna, Sweden, 23-27 March 1992, Eur. Space Agency Spec. Publ., ESA SP$335,417$.
Jacquey, C., J. A. Sauvaud, and J. Dandouras (1991), Location and propagation of the magnetotail current disruption during substorm expansion: Analysis and simulation of an ISEE multi-onset event, Geophys. Res. Lett., 18, 389-392, doi:10.1029/90GL02789.

Jacquey, C., J. A. Sauvaud, J. Dandouras, and A. Korth (1993), Tailward propagating cross-tail current disruption and dynamics of near-Earth tail: A multi-point measurement analysis, Geophys. Res. Lett., 20, 983-986, doi:10.1029/93GL00072.

Johnstone, A. D., et al. (1997), PEACE: A plasma electron and current experiment, Space Sci. Rev., 79, 351-398, doi:10.1023/ A: 1004938001388 .

Kamide, Y., et al. (1994), Ground-based studies of ionospheric convection associated with substorm expansion, J. Geophys. Res., 99, 19,45119,466, doi:10.1029/94JA01625

Liang, J., G. J. Sofko, and H. U. Frey (2006), Postmidnight convection dynamics during substorm expansion phase, J. Geophys. Res., 111, A04205, doi:10.1029/2005JA011483.

Lopez, R. E., and A. T. Y. Lui (1990), A multisatellite case study of the expansion of a substorm current wedge in the near-Earth magnetotail, J. Geophys. Res., 95, 8009-8018, doi:10.1029/JA095iA06p08009.

Lopez, R. E., et al. (1990), Multipoint observations of a small substorm, J. Geophys. Res., 95, 18,897-18,912, doi:10.1029/JA095iA11p18897.

Lui, A. T. Y. (1991), A synthesis of magnetospheric substorm models, J. Geophys. Res., 96, 1849-1856, doi:10.1029/90JA02430.

Lui, A. T. Y. (1996), Current disruption in the Earth's magnetosphere: Observations and models, J. Geophys. Res., 101, 13,067-13,088, doi:10.1029/96JA00079.

Lui, A. T. Y. (2000), Highlights on how to interpret auroral observation in terms of plasma sheet processes, in Proceedings of 5th International Conference on Substorms, St. Petersburg, Russia, May 16-20, 2000 Eur. Space Agency Spec. Publ., ESA SP 443, 231-234.

Lui, A. T. Y. (2006), Extraction of source location parameters from observed particle velocity distribution, Geophys. Res. Lett., 33, L21108, doi:10.1029/2006GL027922.

Lui, A. T. Y., and Y. Kamide (2003), A fresh perspective of the substorm current system and its dynamo, Geophys. Res. Lett., 30(18), 1958, doi:10.1029/2003GL017835.

Lui, A. T. Y., et al. (1988), A case study of magnetotail current sheet disruption and diversion, Geophys. Res. Lett., 15, 721-724, doi:10.1029/GL015i007p00721.

Lui, A. T. Y., et al. (1999), Near-Earth dipolarization: Evidence for a nonMHD process, Geophys. Res. Lett., 26, 2905-2908, doi:10.1029/ 1999GL003620

Lui, A. T. Y., et al. (2000), Conjunction of tail satellites for substorm study: ISTP event of 1997 January 2, Geophys. Res. Lett., 27, 1831-1834, doi:10.1029/1999GL010772.

Lui, A. T. Y., et al. (2007), Prelude to THEMIS tail conjunction, Ann. Geophys., 25, 1001-1009.

Mukai, T., et al. (1994), The low energy particle (LEP) experiment onboard the GEOTAIL satellite, J. Geomagn. Geoelectr., 46, 669-692.

Nagai, T., et al. (1998), Structure and dynamics of magnetic reconnection for substorm onsets with Geotail observations, J. Geophys. Res., 103, 4419-4440, doi:10.1029/97JA02190.

Nakamura, R., et al. (2001), Earthward flow bursts, auroral streamers, and small expansions, J. Geophys. Res., 106, 10,791-10,802, doi:10.1029/ 2000JA000306.

Nakamura, R., et al. (2002), Motion of the dipolarization front during a flow burst event observed by Cluster, Geophys. Res. Lett., 29(20), 1942, doi:10.1029/2002GL015763.

Nakamura, R., et al. (2004), Spatial scale of high-speed flows in the plasma sheet observed by Cluster, Geophys. Res. Lett., 31, L09804, doi:10.1029/ 2004GL019558.

Ohtani, S., K. Takahashi, and C. T. Russell (1992), Radial expansion of the tail current disruption during substorms: A new approach to substorm onset region, J. Geophys. Res., 97, 3129-3136, doi:10.1029/ 91JA02470.

Ohtani, S., et al. (1998), AMPTE/CCE - SCATHA simultaneous observations of substorm-associated magnetic fluctuations, J. Geophys. Res., 103, 4671 - 4682, doi:10.1029/97JA03239.

Ohtani, S., H. J. Singer, and T. Mukai (2006), Effects of the fast plasma sheet flow on the geosynchronous magnetic configuration: Geotail and GOES coordinated study, J. Geophys. Res., 111, A01204, doi:10.1029 2005JA011383.

Pritchett, P. L., and F. V. Coroniti (2002), Consequences of current interruption for plasma sheet dynamics, J. Geophys. Res., 107(A9), 1254, doi:10.1029/2001JA009000.

Rème, H., et al. (2001), First multispacecraft ion measurements in and near the Earth's magnetosphere with the identical Cluster ion spectrometry (CIS) experiment, Ann. Geophys., 19, 1303-1354. 
Roux, A., et al. (1991), Plasma sheet instability related to the westward traveling surge, J. Geophys. Res., 96, 17,697-17,714, doi:10.1029/ 91JA01106.

Samson, J. C., et al. (1991), Observations of a detached discrete arc in association with field line resonances, J. Geophys. Res., 96, 15,68315,695, doi:10.1029/91JA00796.

Samson, J. C., L. L. Cogger, and Q. Pao (1996), Observations of field line resonances, auroral arcs, and auroral vortex structures, J. Geophys. Res., 101, 17,373-17,383, doi:10.1029/96JA01086.

Sauvaud, J. A., et al. (1984), A multisatellite study of the plasma sheet dynamics at substorm onset, J. Geophys. Res., 11, 500-503.

Sergeev, V. A., et al. (2005), Transition from substorm growth to substorm expansion phase as observed with a radial configuration of ISTP and Cluster spacecraft, Ann. Geophys., 23, 2183-2198.

Sergeev, V., et al. (2007), Observation of repeated intense near-Earth reconnection on closed field lines with Cluster, Double Star, and other spacecraft, Geophys. Res. Lett., 34, L02103, doi:10.1029/ 2006GL028452.

Shiokawa, K., W. Baumjohann, and G. Haerendel (1997), Braking of highspeed flows in the near-Earth tail, Geophys. Res. Lett., 24, 1179-1182, doi:10.1029/97GL01062.

Shiokawa, K., et al. (2005), Magnetic field fluctuations during substormassociated dipolarizations in the nightside plasma sheet around $\mathrm{X}=-10$ $R_{\mathrm{E}}, J$. Geophys. Res., 110, A05212, doi:10.1029/2004JA010378.

Tsuruda, K., et al. (1994), Electric field measurements on Geotail satellite, J. Geomagn. Geoelectr., 46, 693-711.
Tsyganenko, N. A. (1995), Modeling the Earth's magnetospheric magnetic field confined within a realistic magnetopause, J. Geophys. Res., 100, 5599-5612, doi:10.1029/94JA03193.

Volwerk, M., et al. (1996), Solitary kinetic Alfvén waves: A study of the Poynting flux, J. Geophys. Res., 101, 13,335-13,343, doi:10.1029/ 96JA00166

Williams, D. J., et al. (1994), GEOTAIL energetic particles and ion composition instrument, J. Geomagn. Geoelectr., 46, 39-57.

I. V. Alexeev, A. N. Fazakerley, and A. P. Walsh, Mullard Space Science Laboratory, Holmbury St. Mary, Dorking, Surrey RH5 6NT, UK.

M. W. Dunlop, Space Science and Technology Department, RAL, Chilton, Didcot, Oxon OX11 0QX, UK.

A. Grocott and M. Lester, Department of Physics and Astronomy, University of Leicester, Leicester, LE1 7RH, UK.

M. Henderson, Los Alamos National Laboratory, Los Alamos, NM 87545, USA.

L. M. Kistler and C. Mouikis, Space Science Center, University of New Hampshire, Durham, NH 03824, USA.

A. T. Y. Lui, Johns Hopkins University Applied Physics Laboratory, Laurel, MD 20723, USA.

H. Rème, CESR/CNRS, F-31028 Toulouse, France.

C. Shen and J. K. Shi, Center for Space Science and Applied Research, Chinese Academy of Sciences, Beijing 10080, China.

M. Volwerk and T. L. Zhang, Space Research Institute, Austrian Academy of Sciences, A-8042, Graz, Austria. 